\title{
Financial Aspects Associated with Overuse of Health Resources
}

\author{
Amro Saleem Falah Alamaren ${ }^{1 *}$ and Ahed J Alkhatib ${ }^{2}$ \\ ${ }^{1}$ Department of finance and banking science, Yarmouk University, Jordan \\ ${ }^{2}$ Department of Legal Medicine, Jordan University of Science and Technology, Jordan
}

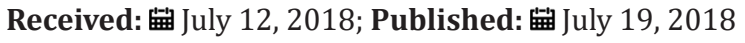

*Corresponding author: Amro Saleem Falah Alamaren, Department of finance and banking science, Yarmouk University, Faculty of economics and administrative sciences, Jordan, Tel: 0096279777 4664; Email: amro_amaren@yahoo.com

\begin{abstract}
Financial support is a very crucial element in maintaining health services. The purpose of this study was to review the literature for financial aspects associated with overuse of health services. The results of this study indicated that the overused health services have become an issue with great concern since it represents high cost that is not justified. There have been calls from the UK health settings to save $\$ 22$ billion from this issue and similar calls have been raised in the US to save $\$ 66$ billion resulting from overused health services. However, a concept called, moral hazard, has been used to address ethical aspects associated with overused health services. Taken together, overused health services are not always good for the interest of patients. Overused health services are interrelated with over testing and exposing patients to undesired outcomes.
\end{abstract}

Keywords: Overused Health Services; Over Testing; Moral Hazards; Calls; Welfare

\section{Introduction}

\section{Finance of Healthcare Services}

Financing implies the existence of both sources and level of financial [1]. It is one of the main concerns associated with constructing the health system in any country is to determine the funding source of the health systems [2]. The main funding agent for health sector is the government in most countries) [3,4]. It has been indicated to the existence of four main sources of finance to fund health sector including governments, private sources, health insurance and external sources [5]. Government financing includes expenditures of health either central or local in addition to that of public corporations [6]. Private financing includes two approaches, direct and indirect. Direct financing involves personal payments received by a variety of providers. On the other hand, indirect payment involves the funds received by employer including coverage, other non-governmental agents such as charity fund raising projects [7]. Health insurance involves government or social insurance, private insurance, and employer -based insurance [8].

\section{Overuse of Health Services}

It is not an easy mission to reach the appropriate diagnosis of diseases in primary care settings [9]. Several factors act to complicate reaching diagnosis such as the existence of poorly differentiated symptoms, multiple complaints, o in addition to some elements relating to psychological or social distress [10]. It has been estimated that in approximately $40 \%$ of primary care consultations, there is a need for diagnostic tests due to insufficiency of evidence from history and physical examination [11,12]. It has been estimated that consultation in primary care are highly prevalent, $90 \%$ in the UK [13], and 55\% in the USA [14]. Taking into consideration the calls for saving of $£ 22$ billion from the UK's National Health Service [15], and similar calls from US Medicare deficit predicted by 2023 to save $\$ 660$ billion (Fisher, Bynum, Skinner, 2009) [16], emphasizes the importance of diagnostic testing to sustain healthcare systems [17].

\section{Overused medical tests}

Across medical literature regarding the overused medical tests reveals the overusing of 11 tests more than $50 \%$ of the time, while echocardiography was overused at different rates [9].

\section{Source of funding and the outcome of health aspects}

Haugen [18] conducted a study about the impact of the source of funding on the outcome of health care. The study aimed to investigate the impact of three different health care financing models on the mortality from cardiovascular diseases. The financing models included the National Health Service model, the Social Health Insurance model, and the Private Health Insurance model. The findings of the study showed that lower mortality rates were less in both the National Health Service model and the Social Health Insurance model compared with the Private Health Insurance model. Furthermore, the performance of The Social 
Health Insurance model was better than the National Health Service model.

\section{Reducing overuse of medical services and patient safety}

Lipitz-Snyderman and Korenstein [19] conducted a study to address the issue of reducing unnecessary medical care in the context of patient safety. Furthermore, there is a problem in identifying the persons who are responsible for determining the aspects of overuse. The issues of patient safety occupy a great concern of hospitals which implies the overuse policy should be planned carefully. According to the Institute of Medicine [20], quality of care is viewed as a measuring scale into which extent the health services submitted for people are expected to reach the planned health outcomes and cope with professional knowledge. Problems associated with health care quality were categorized as underuse (inability to offer appropriate service benefiting the patient), misuse (choosing appropriate service without benefiting patient due to complications that do not permit the implementation of the service), and overuse (the used service implies the exceeding of potential harm to potential of benefit) [21]. Overuse of medical services (i.e., doing too much) has gained much attention to optimize care value in terms of benefit and cost. Low value care implies the presence of healthcare services that have small potential benefits with less expensive cost [22]. According to the study of Brownlee et al. [23], low-value care involves the presence of overused services and services with increased cost in comparison with other options that give similar benefit. Overuse involves the use of various terms such as overtreatment (treatments are harmful for patients more than benefiting), overtesting (tests that harm more than benefiting patients), and over diagnosis (making diagnosis of irrelevant clinical conditions).

\section{Ethics finance and overused of health services}

Barati et al. [24] conducted a study to review the ethical aspects associated with using health services. The results of this study showed that health insurance contracts involve the payment of high treatment costs for disease prevention to inhibit proposed harm or disease since the patient participates partially in the cost. This behavior has adverse consequences such as increased cost of insuring agents and the health system, decreased welfare, wasted resources, and decreased insurance coverage. Taken together, identifying ethical aspects associated with overused health services helps in avoiding moral hazards, in determining causes and consequences as well as control strategies and preventing unwanted outcomes.

\section{Conclusion}

In this study, we reviewed the literature for financial aspects related to overused health services. It has been found that overused health services, doing more for the patients, involves exposing patients to harm rather than benefiting them from one side and involves high level of financial costs. The question is how to reduce overusing of health services without affecting the safety of patients. In this regard, we recommend addressing these points on the community level and to increase the ethical standards to put the right health expenditures in the right place. Overused health services has impacts on other community sectors and reduces the welfare level.

\section{References}

1. Gaal P, Jakab M, Shishkin S (2010) Strategies to address informal payments for health care Implementing health financing reform: lessons from countries in transition. Brussels, European Observatory on Health Policies and Systems.

2. Kutzin J (2009) Bismarck meets Beveridge on the Silk Road: coordinating funding sources to create a universal health financing system in Kyrgyzstan. Bulletin of the World Health Organization 87: 549-554.

3. (2017) Global Burden of Disease Financing Global Health Collaborator Network. Evolution and patterns of global health financing 1995-2014: development assistance for health, and government, prepaid private, and out-of-pocket health spending in 184 countries. The Lancet.

4. (2017) Institute for Health Metrics and Evaluation (IHME). Financing Global Health 2016: Development Assistance, Public and Private Health Spending for the Pursuit of Universal Health Coverage. Seattle.

5. Greene, Joshua E (2011) Public Finance: An International Perspective. Hackensack, New Jersey: World Scientific. p. 500.

6. Olakunde BO (2012) Public health care financing in Nigeria: Which way forward? Ann Nigerian Med 6: 4-10.

7. Motaze NV, Chi CP, Ongolo-Zogo P, Ndongo JS, Wiysonge CS, et al. (2015) Government regulation of private health insurance. The Cochrane Database of Systematic Reviews Advance online publication.

8. O Sullivan JW, Albasri A, Nicholson BD (2018) Overtesting and under testing in primary care: a systematic review and meta-analysis. BMJ Open 8: e018557.

9. Foot C, Naylor C, Imison C (2010) The quality of GP diagnosis and referral.

10. Heneghan C, Glasziou P, Thompson M (2009) Diagnostic strategies used in primary care. BMJ 338: b946.

11. Koch H, van Bokhoven MA, Ter Riet G (2009) Ordering blood tests for patients with unexplained fatigue in general practice: what does it yield? Results of the VAMPIRE trial. Br J Gen Pract 59: 93-100.

12. Hobbs FDR, Bankhead C, Mukhtar T (2016) Clinical workload in UK primary care: a retrospective analysis of 100 million consultations in England. Lancet 387: 2323-23230.

13. (2012) Centers for Disease Control and Prevention, National Center for Health Statistics. National ambulatory medical care survey.

14. Alderwick H, Robertson R, Appleby J (2015) Better value in the NHS: The role of changes in clinical practice.

15. Fisher ES, Bynum JP, Skinner JS (2009) Slowing the growth of health care costs-lessons from regional variation. N Engl J Med 360: 849-852.

16. Appleby J, Thompson J, Jabbal J (2016) Quarterly Monitoring Report: How is the NHS performing? King's Fund pp. 1-42.

17. Thordis Marie Widvey Haugen (2014) The Politics of Health Care Financing Models: Does the Source of Funding Matter for Health Care Outcome? Master's Thesis, Department of Political Science Faculty of Social Science, University of Oslo.

18. Allison Lipitz-Snyderman, Deborah Korenstein (2017) Reducing overuse - is patient safety the answer? JAMA 317(8): 810-811.

19. Government of Malawi (2015) Health Sector Mid-Year Review. Paper presented on Proposed Malawi Health Fund at Crossroads Hotel Lilongwe, Malawi.

20. Lohr KN (1990) Institute of Medicine Division of Health Care Services. Institute of Medicine (U.S.) Committee to Design a Strategy for Quality Review and Assurance in Medicare., United States. Medicare: a strategy for quality assurance Washington, USA. 
21. Chassin MR, Galvin RW (1998) The urgent need to improve health care quality. Institute of Medicine National Roundtable on Health Care Quality. JAMA 280(11): 1000-1005.

22. Schpero WL (2014) Limiting low-value care by "choosing wisely". Virtual Mentor 16(2): 131-134.

\section{ISSN: 2574-1241}

DOI: 10.26717/BJSTR.2018.07.001444

Amro Saleem Falah Alamaren. Biomed J Sci \& Tech Res

(C) This work is licensed under Creative

Submission Link: https://biomedres.us/submit-manuscript.php
23. Brownlee S, Chalkidou K, Doust J, Elshaug AG, Glasziou P, et al. (2017) Evidence for overuse of medical services around the world. Lancet (10090): 156-168.

24. Barati M, Azami F, Nagdi B, Foladi M, Hajimaghsoudi M, et al. (2018) Moral Hazards in Providing Health Services: A Review of Studies. Evidence Based Health Policy, Management \& Economics 2(1): 61-69.

Assets of Publishing with us
BIOMEDICAL
RESEARCHES

